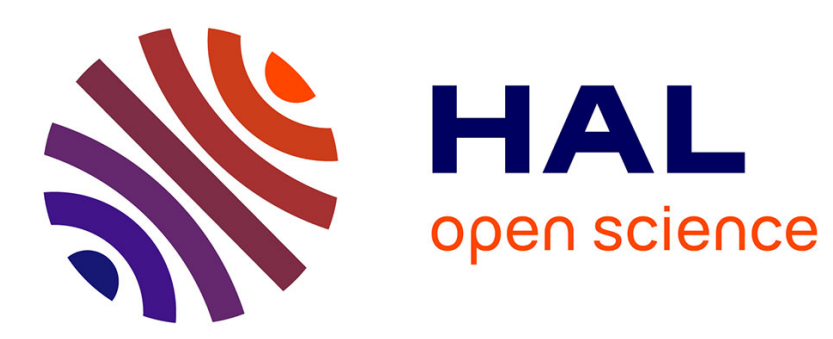

\title{
Collective Microoptics on Fiber Ribbon for Optical Interconnecting Devices
}

P. Chanclou, M Thual, J Lostec, D Pavy, M Gadonna, A. Poudoulec

\section{To cite this version:}

P. Chanclou, M Thual, J Lostec, D Pavy, M Gadonna, et al.. Collective Microoptics on Fiber Ribbon for Optical Interconnecting Devices. Journal of Lightwave Technology, 1999, 17 (5), pp.924-928. hal02920576

\section{HAL Id: hal-02920576 https://hal.science/hal-02920576}

Submitted on 25 Aug 2020

HAL is a multi-disciplinary open access archive for the deposit and dissemination of scientific research documents, whether they are published or not. The documents may come from teaching and research institutions in France or abroad, or from public or private research centers.
L'archive ouverte pluridisciplinaire HAL, est destinée au dépôt et à la diffusion de documents scientifiques de niveau recherche, publiés ou non, émanant des établissements d'enseignement et de recherche français ou étrangers, des laboratoires publics ou privés. 


\title{
Collective Micro-Optics on Fibre Ribbon for Optical Interconnecting Devices
}

\author{
P. Chanclou, M. Thual, J. Lostec, D. Pavy, M. Gadonna and A. Poudoulec. \\ FRANCE TELECOM, CNET, DTD/PIH \\ 2, avenue Pierre Marzin, F22307 LANNION CEDEX FRANCE
}

\begin{abstract}
New micro-optics are proposed to interconnect Single-Mode Fibre (SMF) ribbons. These micro-optics allow the increase of the fibre spot size. Low loss, wide misalignment tolerances, long working distance, and low cost could be achieved. The fabrication process and experimental results are presented.
\end{abstract}

\section{Introduction}

The large implementation of the future optical networks will induce a growing demand for optical parallel data transmission and switching systems. The development of low cost and highly dense packaged interconnection devices is therefore essential. Due to small mode field diameter of the SMF, conventional connectors using butt coupling has tight alignment tolerances, leading to critical fabrication steps. In order to relax these tolerances several methods which enlarge the MFD of the SMF have been reported $[1,2,3,4]$. The new proposed technique here is particularly suitable for mass production and cost effectiveness. It is based on fibre configuration and on simple collective fabrication process. It consists in splicing a micro-optics, arranged in fibre ribbon shape, at the end face of the SMF ribbon. As shown in Fig. 1, these micro-optics are composed of two welded sections: a graded index (GRIN) fibre array and a coreless silica array section. The spot size and the working distance are adjusted by changing the length of GRIN and silica sections. One of the most promising applications of these micro-optics arrays is the optical coupling between fibre ribbons and arrays of passive or active components such as fibres, collimators [5], laser diodes (LD), vertical-cavity surface-emitting laser array (VCSEL)... This paper deals with the interconnection of SMF ribbons.

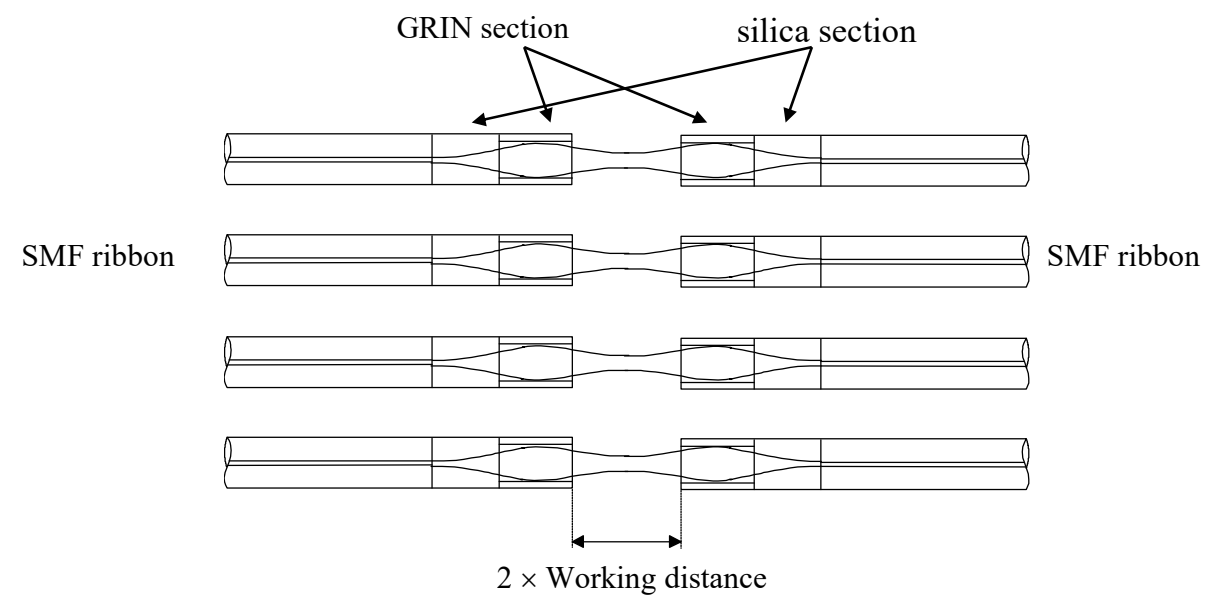

Fig. 1. Schematic view of optical coupling arrangement.

\section{Fabrication Process}

The fabrication process of micro-optics has already been published [6,7]. It is illustrated in Fig. 2. We use G652 single-mode fibre, 85/125/250 graded index fibre and a home-made coreless silica fibre. The microoptics feasibility study was made on a 4-fibre ribbon; however, the number of fibres is only limited by the capacity of the available splicing machine (12 fibres at present). 


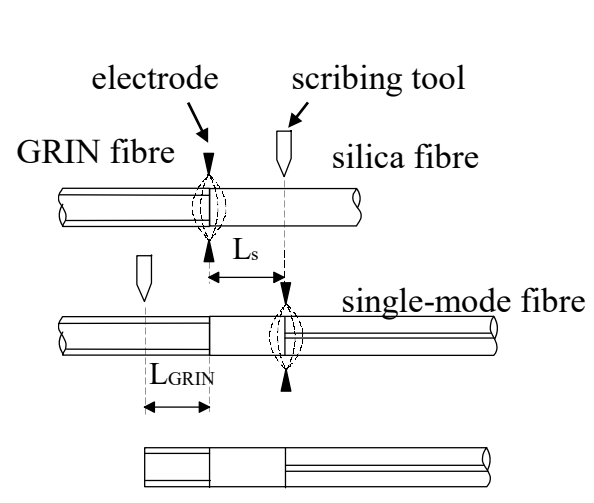

Fig. 2. Micro-optics fabrication process.

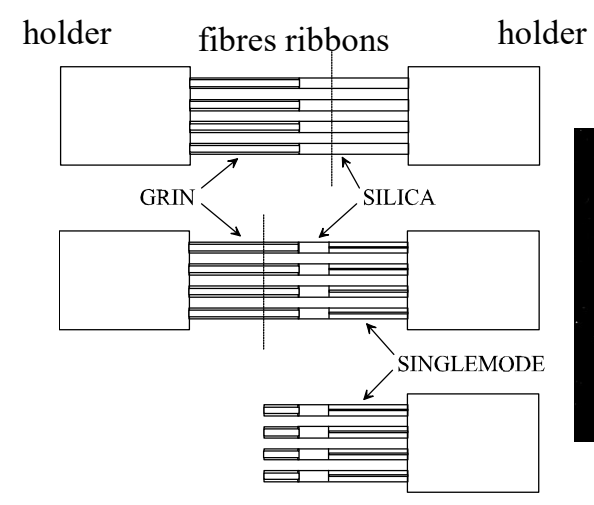

Fig. 3. Collective fabrication process.

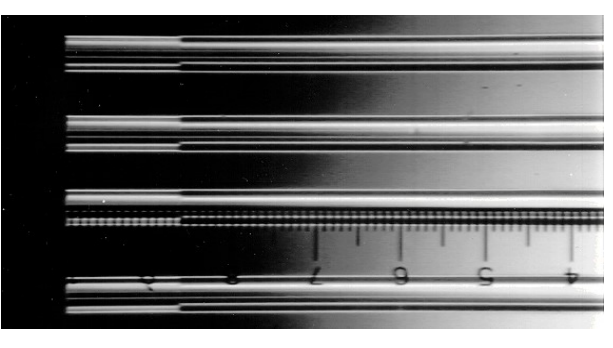

Fig. 4. Photograph of the micro-optics ribbon.

Using an arc-discharge fibre splicer, the GRIN ribbon is first spliced to the silica ribbon. The silica ribbon is then cleaved at a distance $\mathrm{L}_{\mathrm{S}}$ from the silica/GRIN splicing. The GRIN and silica ribbon are spliced to the SMF ribbon. Finally the GRIN part of ribbon is cleaved at a distance $\mathrm{L}_{\text {GRIN }}$ from the silica/GRIN splicing. To adjust the lengths of sections we locate the splices of ribbons with a visual unit. And before cleaving we move back the fibres ribbon of the appropriate length. The reproducibility of the lengths is about $\pm 2 \mu \mathrm{m}$ for each section of ribbon. The two splicing losses are below $0.1 \mathrm{~dB}$ each. During the fabrication process (Fig. 3), we only manipulate fibres ribbons. Fig. 4 shows a view of the micro-optics ribbon. The outer diameter of $125 \mu \mathrm{m}$ is maintained along the micro-optics and is given by the largest diameter accuracy of fibres used in the fabrication process. Neither diameter bubble or conical end shape is observed during the fabrication process. In our work a $126-0 /+0.5 \mu \mathrm{m}$ ferrule receives $85 \%$ of fabricated micro-optics.

First technoeconomical analysis shows a very attractive cost of this micro-optics. This is mainly due to the negligible cost of the raw materials, the few number of steps, the collective treatment, the use of commercialy available tools and the high yield of the whole process.

\section{Focusing Properties and Performances}

The role of the silica section is to expand the optical beam from SMF to the GRIN section. It also makes possible to optimise the spot size at the end-face of the micro-optics and to maintain and align the GRIN section at the appropriate distance from the SMF. Fig. 5 shows the spot size diameter at the focal point versus length of GRIN for different lengths of silica: 0 to $600 \mu \mathrm{m}$. The maximum silica section length $(640 \mu \mathrm{m})$ is discussed in Appendix. The spot size diameter, defined at $1 / \mathrm{e}^{2}$ of the maximum intensity, obtained using micro-optics with $400 \mu \mathrm{m}$ of silica, ranges from 6 to $58 \mu \mathrm{m}$, whereas the mode diameter of the usual SMF is about $10 \mu \mathrm{m}$ at a wavelength $\lambda=1.3 \mu \mathrm{m}$.

Fig. 6 shows the working distance between fibres versus varying lengths of GRIN and silica sections, regarding the interconnection of fibres in air. The theoretical curves are compared with measured values for two lengths of silica $\mathrm{L}_{\mathrm{s}}=0 \mu \mathrm{m}$ and $400 \mu \mathrm{m}$. The maximum working distance for these micro-optics with $400 \mu \mathrm{m}$ of silica, is $2000 \mu \mathrm{m}$. The advantage of beam-expanding by micro-optics is the possibility either to collimate or to focus the optical beam with the desirable property. This micro-optics is modular according to applications. We should note that for a desired spot size diameter or working distance and a given length of silica, two lengths of the GRIN section are possible. We shall choose the micro-optics which have the largest tolerance of fabrication $(> \pm 2 \mu \mathrm{m})$ as concerns section lengths. It corresponds to the part of the curve where the slope is the lowest (Fig. $5)$.

A virtual beam waist could be obtained with different GRIN lengths. It corresponds to the case of a negative working distance where the beam waist is not formed after passing through the micro-optics. In our applications of interconnection of SMF ribbon, only positive working distance is used. As demonstrated in Appendix, with the maximum length of silica, the maximum distance in air between fibres is $4350 \mu \mathrm{m}$ and spot size diameter is ranging from 3.1 to $85 \mu \mathrm{m}$. 


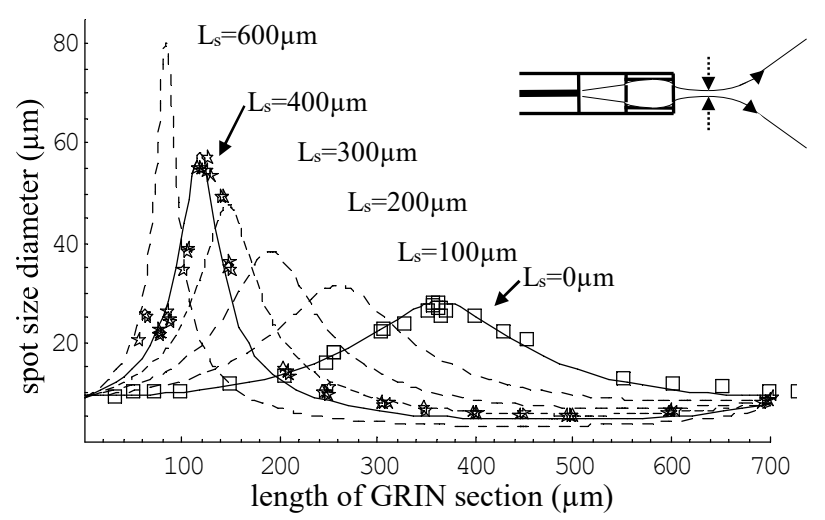

Fig. 5. Spot size diameter at the focal point of the microoptics for two lengths of silica $\mathrm{L}_{\mathrm{s}}=0 \mu \mathrm{m}$ (box) and 400 $\mu \mathrm{m}$ (star).

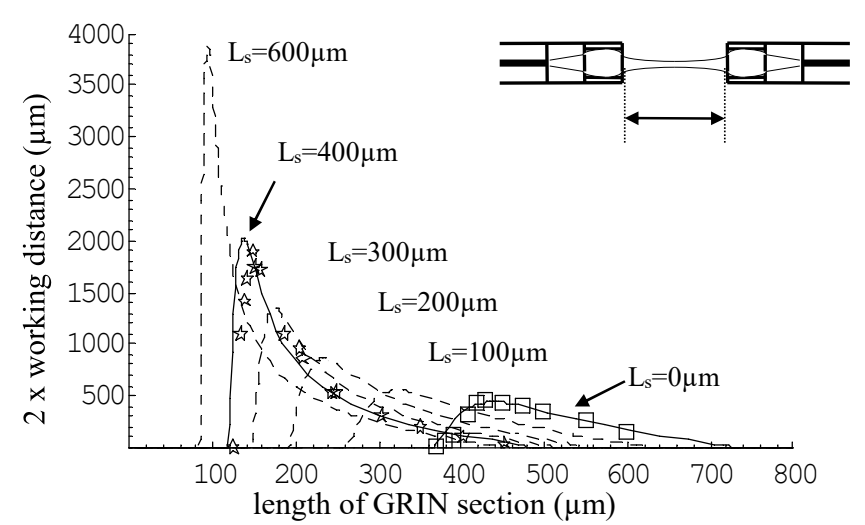

Fig. 6. Working distance between two micro-optics for only two lengths of silica $\mathrm{L}_{\mathrm{s}}=0 \mu \mathrm{m}$ (box) and $400 \mu \mathrm{m}$ (star).

Connection losses have been measured for varying lengths of GRIN and silica sections at $\lambda=1.3 \mu \mathrm{m}$. No index matching is used between fibres so additional coupling loss of $0.3 \mathrm{~dB}$ are induced by Fresnel reflections. However, due to the fact that the end face of micro-optics is not polished, imperfections cause wavefront distortions [8]. The additional loss is estimated to $0.2 \mathrm{~dB}$ which corresponds to a RMS-value $\sigma=30 \mathrm{~nm}$ measured by differential interference pattern method. The use of an index matching provides lower connection loss and larger working distance.

In the configuration without silica section $\left(\mathrm{L}_{\mathrm{s}}=0 \mu \mathrm{m}\right)$, we have achieved a connection loss between ribbons of $0.59 \mathrm{~dB}$ with a standard deviation of $0.14 \mathrm{~dB}$ for a total of 10 connections with different GRIN lengths. The theoretical connection loss is evaluated at $0.6 \mathrm{~dB}$ by the sum of Fresnel reflections, end face imperfections and splicing losses.

By using a length of silica $L_{s}=400 \mu \mathrm{m}$, several micro-optics ribbons have been made with various lengths of GRIN which correspond to various working distances. For example Fig. 7 shows the 16 connections losses of each fibres of two ribbons $\left(\mathrm{L}_{\mathrm{GRIN}}=300 \mu \mathrm{m}\right.$ ). For this length the spacing distance between fibres is $300 \mu \mathrm{m}$ and the average of losses is $-0.8 \mathrm{~dB}$ with a standard deviation of $0.06 \mathrm{~dB}$. As shown in Fig. 8, the measured connections losses of each fibres of different pairs of ribbons is around $0.84 \mathrm{~dB}$ whatever the working distance. The theoretical connection loss for this case, is evaluated at $0.7 \mathrm{~dB}$ with one additional splicing. Fig. 9 shows an histogram of connection losses with a standard deviation of $0.18 \mathrm{~dB}$ for a total of 107 connections of fibres in ribbon configuration.

\begin{tabular}{|c|c|c|c|c|}
\hline $\begin{array}{c}\text { connection } \\
\text { loss }(\mathrm{dB})\end{array}$ & fibre 1 & fibre 2 & fibre 3 & fibre 4 \\
\hline fibre 1 & $-0,88$ & $-0,94$ & $-0,93$ & $-0,88$ \\
\hline fibre 2 & $-0,76$ & $-0,75$ & $-0,76$ & $-0,73$ \\
\hline fibre 3 & $-0,81$ & $-0,72$ & $-0,82$ & $-0,78$ \\
\hline fibre 4 & $-0,78$ & $-0,66$ & $-0,82$ & $-0,79$ \\
\hline
\end{tabular}

\begin{tabular}{|c|c|}
\hline Total & 16 \\
\hline Average & $-0,8 \mathrm{~dB}$ \\
\hline Std. Dev. & $0,06 \mathrm{~dB}$ \\
\hline
\end{tabular}

Fig. 7. An example of connections losses between two ribbons with $\mathrm{L}_{\mathrm{s}}=400 \mu \mathrm{m}$ and $\mathrm{L}_{\mathrm{GRIN}}=300 \mu \mathrm{m}$. 


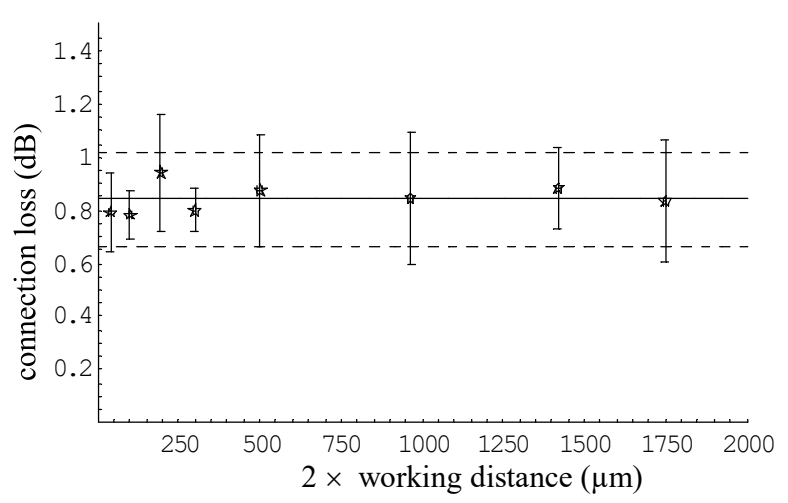

Fig. 8. Connection loss as a function of the working distance $\left(\mathrm{L}_{\mathrm{s}}=400 \mu \mathrm{m}\right.$ and various lengths of GRIN).

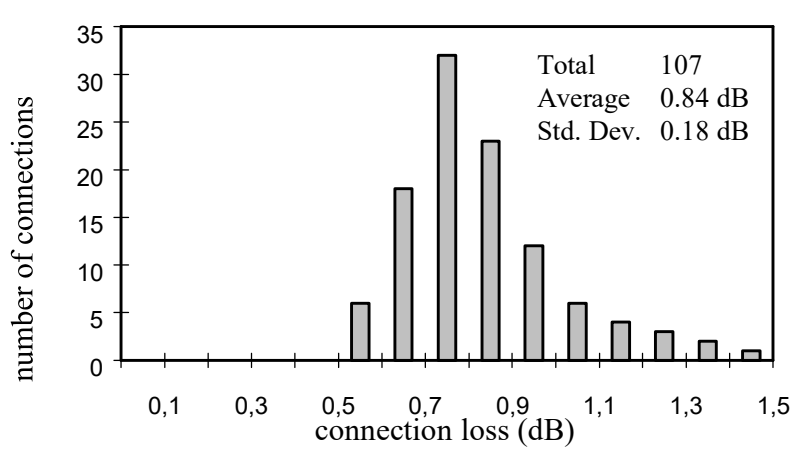

Fig. 9. Connection loss of new micro-optics $\left(\mathrm{L}_{\mathrm{s}}=400 \mu \mathrm{m}\right.$ and various lengths of GRIN).

\section{Misalignment Tolerance}

It is important for packaging design to estimate the influence of misalignment on the fibre coupling. The measurements of the coupling loss as a function of lateral (a) and axial (b) displacements, are shown in Fig. 10 for a micro-optics $\left(\mathrm{L}_{\mathrm{s}}=400 \mu \mathrm{m}\right.$ and $\left.\mathrm{L}_{\mathrm{GRIN}}=130 \mu \mathrm{m}\right)$ having one of the biggest diameter modes $50 \mu \mathrm{m}$. In this configuration the working distance is nil. The optical alignment tolerance is $\pm 12 \mu \mathrm{m}$ in the lateral direction and $-1500 \mu \mathrm{m}$ (backward movement of fibre) in the axial direction for $1 \mathrm{~dB}$ excess loss. Note that the calculated values and experimental results are in good agreement.
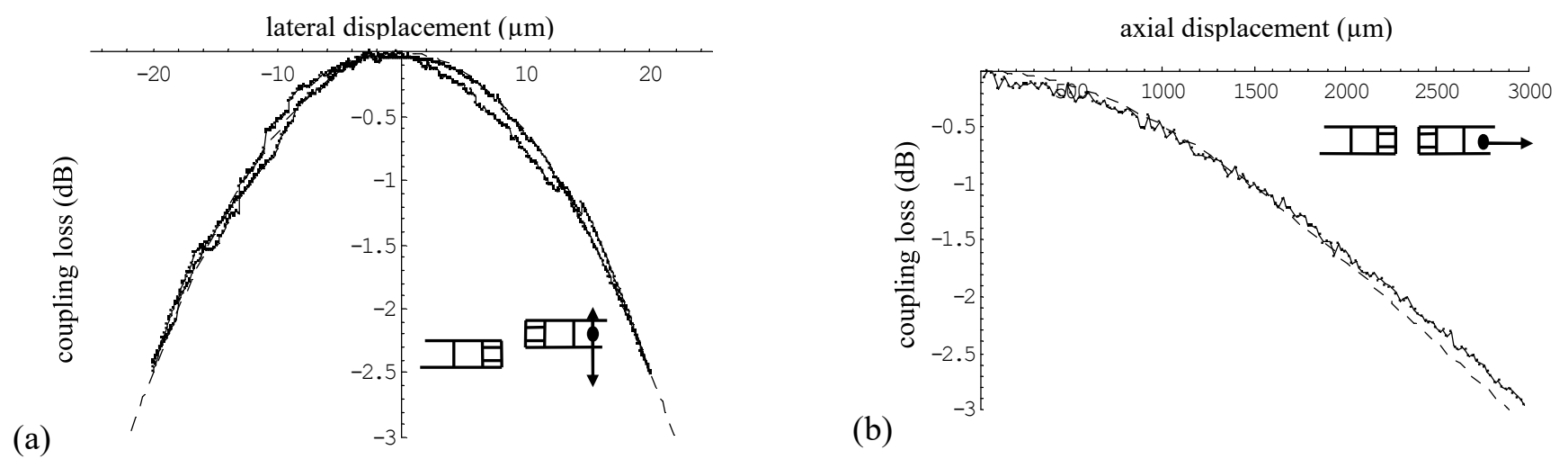

Fig. 10. Coupling-loss characteristics versus lateral (a) and axial (b) displacement of a micro-optics. Dashed lines are theoretical curves.

The optical alignment tolerance for a lateral, axial and angular displacement for $1 \mathrm{~dB}$ excess loss is reported in Fig. 11. The theoretical curves of tolerances are compared with measured axial and lateral alignment tolerance for two lengths of silica $\mathrm{L}_{\mathrm{s}}=0 \mu \mathrm{m}$ and $400 \mu \mathrm{m}$ and various lengths of GRIN. The best lateral (a) and axial (b) offset tolerances for the micro-optics ( \pm 14 and $\pm 2060 \mu \mathrm{m}$, respectively) are six and forty times higher than those for the SMF ( \pm 2.2 and $\pm 52 \mu \mathrm{m}$, respectively). The best angular (c) tolerance $\left( \pm 5^{\circ}\right)$ for the microoptics is two times higher than for the SMF $\left( \pm 2.5^{\circ}\right)$. As an example, for an application which needs $1000 \mu \mathrm{m}$ air distance between fibres, we could choose a micro-optics with $400 \mu \mathrm{m}$ of silica and $180 \mu \mathrm{m}$ of GRIN and we would achieve $\pm 4 \mu \mathrm{m}, \pm 170 \mu \mathrm{m}, \pm 1.3^{\circ}$ lateral, axial and angular tolerances. 
(a)

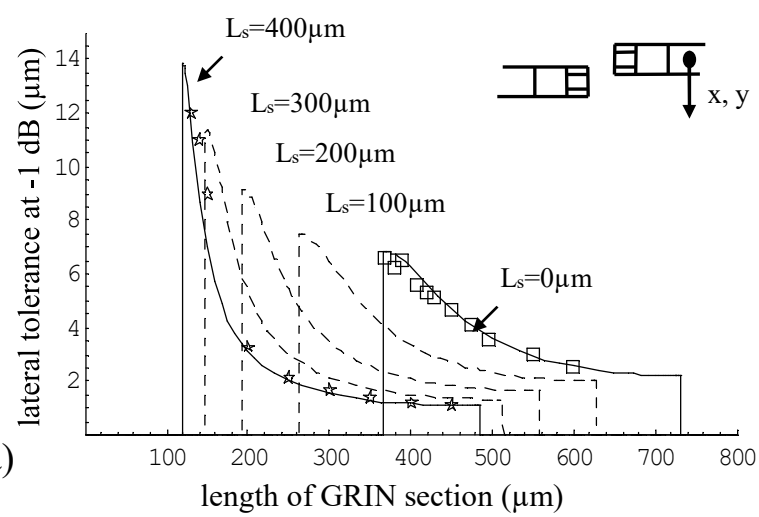

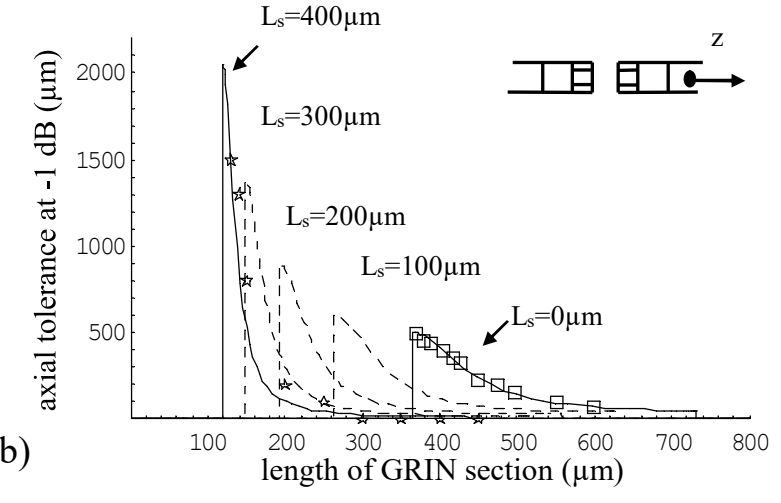

(b)

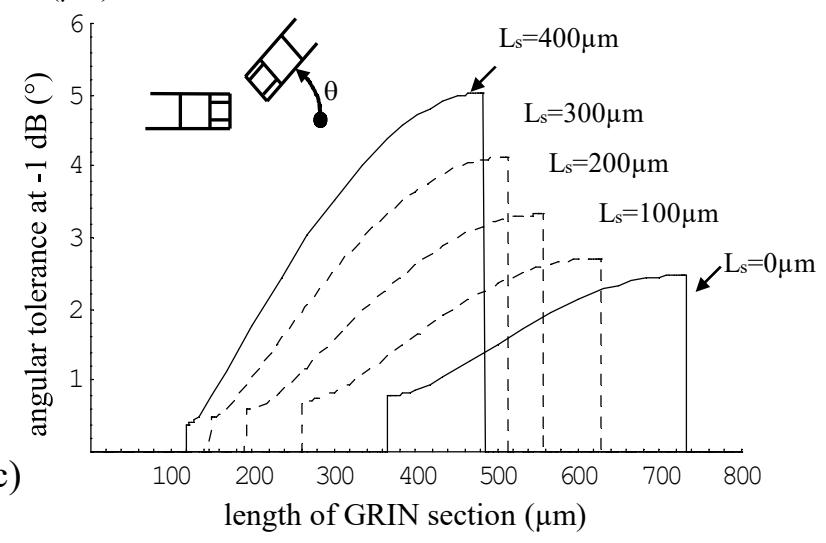

Fig. 11. Lateral (a), axial (b) and angular (c) alignment tolerance for $1 \mathrm{~dB}$ excess loss for two lengths of silica $\mathrm{L}_{\mathrm{s}}=0 \mu \mathrm{m}(\mathrm{box})$ and $400 \mu \mathrm{m}$ (star) and various lengths of GRIN.

\section{Conclusion}

We have presented new micro-optics for expanding fibre beam on fibre ribbon. The spot size diameter can be expanded up to $58 \mu \mathrm{m}$. A ribbon fibre interconnection has been demonstrated giving an insertion loss of $0.84 \mathrm{~dB}$ between two micro-optics ribbons over a $1750 \mu \mathrm{m}$ air gap and large lateral tolerance $\pm 12 \mu \mathrm{m}$ for $1 \mathrm{~dB}$ excess loss. The theory gives a maximum distance in air between fibres of $4350 \mu \mathrm{m}$ and spot size diameter ranging from 3.1 to $85 \mu \mathrm{m}$. The fabrication process needs few simple and collective steps and is particularly suitable for mass production and low cost. The outer fibre diameter of $125 \mu \mathrm{m}$ is maintained along the microoptics and allow them to be inserted in ferrules. Moreover, due to the large tolerance of misalignment it is possible to arrange fibre in an array. The working distance can be large enough for the insertion of passive or active components between the fibres and therefore to design low loss collective in line optical devices. 


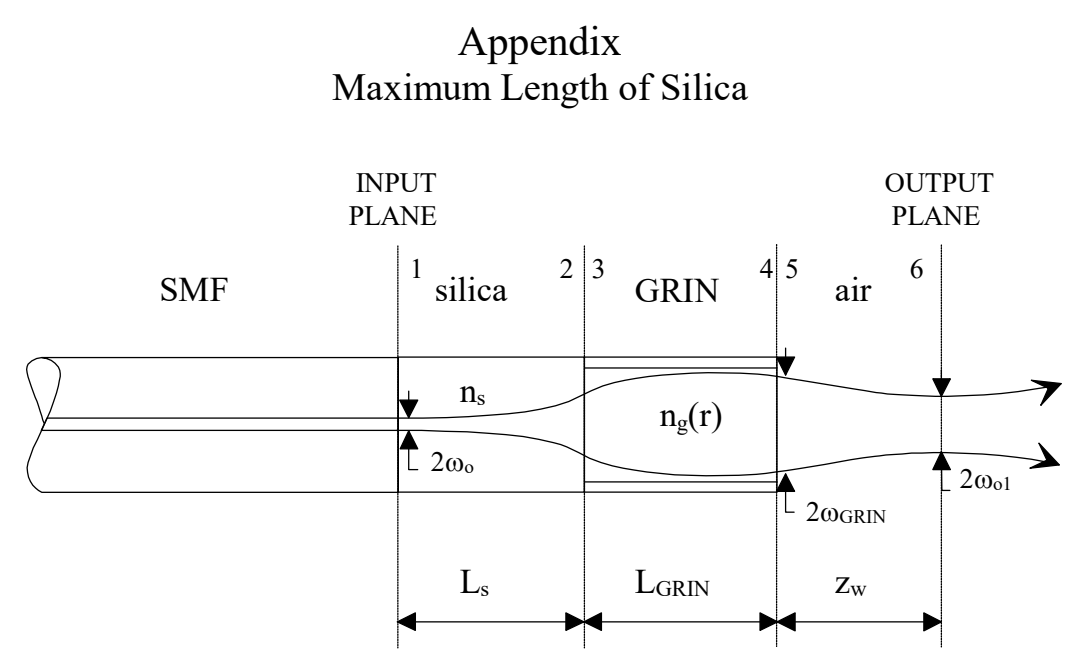

Fig. 12. Propagation of the paraxial Gaussian beam through micro-optics.

The ray matrix transformation [9] is used to describe the beam transformation by the micro-optics. A precedent ray matrix analysis has been presented by W. L. Emkey and C. A. Jack [10] where the optical system is quite similar. The main differences are that, as shown in Fig. 12, in our case a silica section is inserted between SMF and GRIN fibre and final medium is air. So $\mathrm{n}_{2}=1$ and $\mathrm{n}_{1}=\mathrm{n}_{\mathrm{s}}$ is the refractive index of silica. The GRIN section has a $\phi_{\mathrm{g}}=85 \mu \mathrm{m}$ core diameter where the dependence of the refractive index is given by

$$
\begin{aligned}
\mathrm{n}(\mathrm{r}) & =\mathrm{n}_{\mathrm{o}}\left(1-\frac{\mathrm{g}^{2}}{2} \mathrm{r}^{2}\right) \quad \text { for } 0 \leq \mathrm{r} \leq \phi_{\mathrm{g}} \\
& =\mathrm{n}_{\mathrm{cl}} \text { for } \phi_{\mathrm{g}}<\mathrm{r} \leq \phi_{\mathrm{f}}
\end{aligned}
$$

$\mathrm{r}$ is the radial position from the axis, $\mathrm{n}_{\mathrm{o}}=1.471$ is the refractive index along the optical axis and $\mathrm{g}$ is quadratic gradient constant equal to $4.294 \mathrm{~mm}^{-1}$ at $1.3 \mu \mathrm{m}$. The external fibre diameter is $\phi_{\mathrm{f}}=125 \mu \mathrm{m}$. The index of silica and cladding of GRIN section are equal $\mathrm{n}_{\mathrm{s}}=\mathrm{n}_{\mathrm{cl}}=1.447$. All components of $\mathrm{ABCD}$ matrix is calculated as $\mathrm{A}=\cos \left(\mathrm{gL}_{\mathrm{GRIN}}\right)-\mathrm{n}_{\mathrm{o}} \mathrm{z}_{\mathrm{w}} \mathrm{g} \sin \left(\mathrm{gL}_{\mathrm{GRIN}}\right)$

$\mathrm{B}=\left(\mathrm{L}_{\mathrm{s}}+\mathrm{n}_{\mathrm{s}} \mathrm{z}_{\mathrm{w}}\right) \cos \left(\mathrm{gL}_{\mathrm{GRIN}}\right)+\left(\frac{\mathrm{n}_{\mathrm{s}}}{\mathrm{n}_{\mathrm{o}} \mathrm{g}}-\mathrm{n}_{\mathrm{o}} \mathrm{gL}_{\mathrm{s}} \mathrm{z}_{\mathrm{w}}\right) \sin \left(\mathrm{gL}_{\mathrm{GRIN}}\right)$

$\mathrm{C}=-\mathrm{n}_{\mathrm{o}} \mathrm{g} \sin \left(\mathrm{gL}_{\mathrm{GRIN}}\right)$

$\mathrm{D}=\mathrm{n}_{\mathrm{s}} \cos \left(\mathrm{gL}_{\mathrm{GRIN}}\right)-\mathrm{n}_{\mathrm{o}} \mathrm{gL} \mathrm{s}_{\mathrm{s}} \sin \left(\mathrm{gL}_{\mathrm{GRIN}}\right)$

The input plane contains the end face of a SMF and the beam waist $\omega_{0}$. The output plane contains the final beam waist $\omega_{01}$ formed after passing through micro-optics, which is defined as

$\omega_{o 1}=\omega_{0}\left\{n_{s} \frac{A^{2}+a^{2} B^{2}}{A D-B C}\right\}^{1 / 2}$

where

$\mathrm{a}=\frac{\lambda}{\pi \omega_{\mathrm{o}}{ }^{2} \mathrm{n}_{\mathrm{s}}}$.

However, in the case where the silica section is too long the Gaussian beam could be truncated by the cladding of the GRIN fibre. The beam waist in GRIN medium must be lower than $\phi_{\mathrm{g}}$ core diameter. The spot size $\omega_{\mathrm{GRIN}}$ in the end face of the GRIN section is defined at $\mathrm{Z}_{\mathrm{w}}=0$ and

$\omega_{\text {GRIN }}\left(\mathrm{z}_{\mathrm{w}}=0\right)=\omega_{\mathrm{o}}\left\{\cos ^{2}\left(\mathrm{gL}_{\mathrm{GRIN}}\right)+\mathrm{a}^{2}\left(\mathrm{~L}_{\mathrm{s}} \cos \left(\mathrm{gL}_{\mathrm{GRIN}}\right)+\frac{\mathrm{n}_{\mathrm{s}}}{\mathrm{n}_{\mathrm{o}} \mathrm{g}} \sin \left(\mathrm{gL}_{\mathrm{GRIN}}\right)\right)^{2}\right\}^{1 / 2} \leq \frac{\phi_{\mathrm{g}}}{2}$. 
As shown in Fig. 13, the truncation of the beam by the cladding of the GRIN section is negligible when the length of silica section is under $640 \mu \mathrm{m}$ at $1.3 \mu \mathrm{m}$. For this length, the maximum distance in air between fibres is $4350 \mu \mathrm{m}$ and spot size diameter is ranging from 3.1 to $85 \mu \mathrm{m}$.

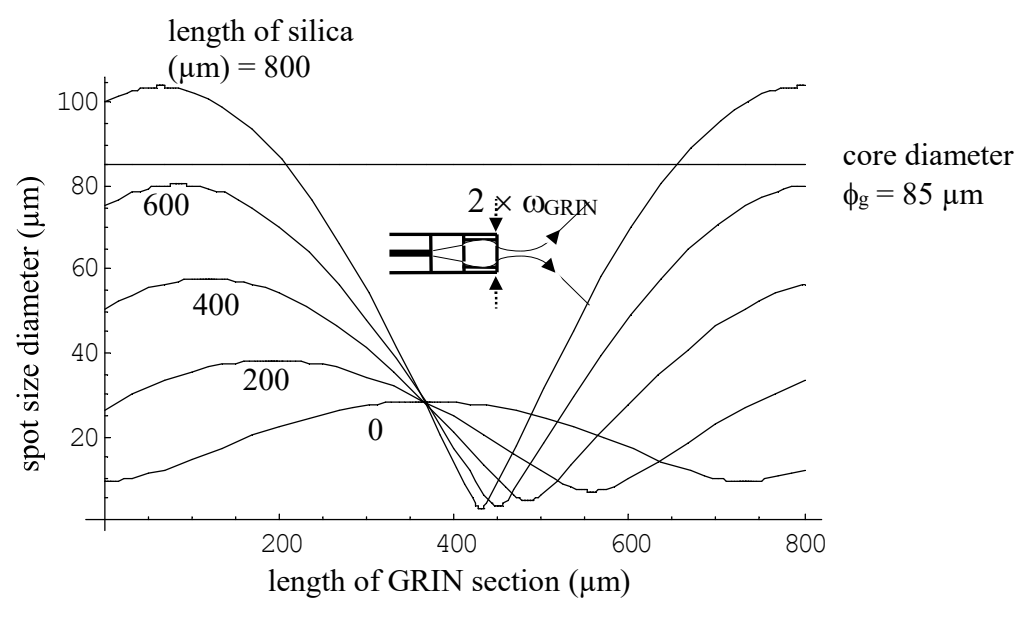

Fig. 13. Maximum spot size as function of the length of silica section at the end face of GRIN section.

\section{References}

[1] K. Furuya, T. C. Chong, and Y. Suematsu, "Low loss splicing of single-mode fibers by tapered-buttjoint method", Trans. IECE Japan, vol. E61, pp. 957, 1978.

[2] N. Amitay, H. M. Presby, F. V. Dimarcello, and K. T. Nelson, "Optical fiber taper: A novel approach to self-aligned beam expansion and single-mode hardware", J. Lightwave Technol., vol. LT-5, pp. 70, 1987.

[3] K. Shiraishi, Y. Aizawa, and S. Kawakami, "Beam expanding fiber using thermal diffusion of the dopant", J. Lightwave Technol., vol. 8, No. 8, 1990.

[4] M. Kihara, M. Matsumoto, T. Haibara, and S. Tomita, "Characteristics of thermally expanded core fiber", J. Lightwave Technol., vol. 10, No. 10, 1996.

[5] A. Purser, J. S. Harper, S. R. Mallinson, "Low cost, single-mode optical fibre beam collimators for use in air-spaced devices, E-FOC89, N³.4.4, 1989.

[6] M. Thual, J. Lostec, P. Auvray, B. Clavel, French patent No 96 10327, August 1996

[7] P. Chanclou, M. Thual, J. Lostec, P. Auvray, J. Caulet, G. Joulie, A. Poudoulec, and B. Clavel, "Highly efficient collective coupling diode array and lensed fibre ribbon", Electronics Letters, vol. 34, №3, pp. 273-274, Feb. 1998.

[8] B. Hillerich, "Influence of lens inperfections with LD and LED to single-mode fiber coupling", ", Journal of Lightwave Technology 7, 77-86 (1989).

[9] H. Kogelnik, "Imaging of Optical Modes - Resonators with Internal Lenses", Bell Syst. Tech. J., vol. 4, pp. 455, 1965.

[10] W. L. Emkey and C. A. Jack, "Analysis and Evaluation of Graded-Index Fiber-Lenses", J. Lightwave Technol., vol. LT-5, No. 9, pp. 1156-1164, 1987. 